\title{
Giant Pubic Lipoma in Normal Individual
}

\author{
Nazan Sivrioglua, b, Eray Copcu ${ }^{\mathrm{a}}$, Murat Sonela ${ }^{\mathrm{a}}$, Banu Aksoy ${ }^{\mathrm{a}}$
}

\begin{abstract}
The lipomas are the most frequently encountered mesenchymal neoplasm in humans. They are usually encapsulated by thin fibrous tissue, and vary in size. We hereby report a giant fibrolipoma that was localized on mons pubis. Pubic area is one of the rare reported regions for fibrolipoma in the literature. A few cases of pubic fibrolipoma were reported in the literature and all the cases were among HIV (+) patients with lipodystrophia. Our case is not only the first pubic giant fibrolipoma but also the first case in normal individual not HIV (+) or lipodistrophic patient.
\end{abstract}

Keywords: Lipoma; Giant; Pubic; HIV

\section{Introduction}

The lipomas are the most frequently encountered mesenchymal neoplasm in humans. They are usually encapsulated by thin fibrous tissue, and vary in size $[1,2]$. The lipomas may change between a few centimeters to huge volumes. The most frequently seen localizations for lipomas are the neck and torso. However, they can be found on any place throughout the body [1]. We hereby report a giant fibrolipoma that was localized on mons pubis.

Manuscript accepted for publication March 17, 2011

aPlastic, Reconstructive and Aesthetic Surgery Department, Adnan Menderes University, Aydin, Turkey

${ }^{\mathrm{b}}$ Corresponding author: Nazan Sivrioglu, Plastic, Reconstructive and Aesthetic Surgery Department, Adnan Menderes University, 09100, Aydin, Turkey. Email: ecopcu@adu.edu.tr

doi: $10.4021 / \mathrm{jmc} 187 \mathrm{w}$

\section{Case Report}

A 48-year-old female patient was admitted to our clinic with the complaint of saccular enlargement on pubis. She mentioned that the mass initially appeared 3 years ago and enlarged slowly. The complaints were mainly about personal hygiene and sexual functions. On physical examination: the mass was $22 \times 15 \times 5 \mathrm{~cm}$ in diameter, smooth, pedinculated and was projected downwards. There was no tenderness and pain on the mass. The medical history of the patient revealed nothing except umbilical hernia operation (Fig. 1). Magnetic resonance imaging demonstrated septation and prominent thickening of subcutaneous tissue (Fig. 2). The neoplasm weighing $1,042 \mathrm{gr}$ was excised with overlaying skin under general anesthesia (Fig. 3). Microscopic evaluation revealed mature adipocytes and dense fibrous connective tissue. The histopathological diagnosis was fibrolipoma. The postoperative recovery was uneventful and the complaints of the pa-

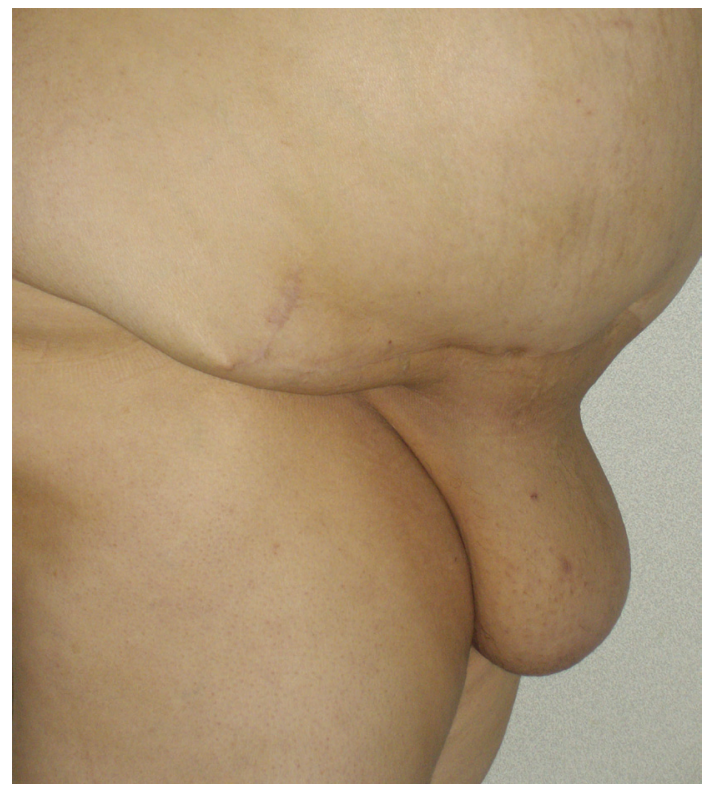

Figure 1. Picture showing saccular enlargement on pubis. 


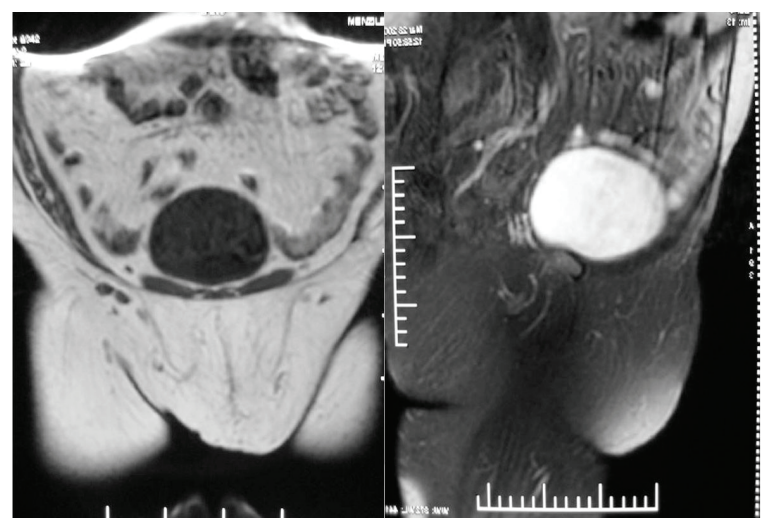

Figure 2. Magnetic resonance imaging demonstrated septation and prominent thickening of subcutaneous tissue.

tient were fully vanished in the meantime.

\section{Discussion}

The lipomas are most frequently encountered neoplasm of soft tissue. Fibrolipoma is a variant of lipomas that contain fibrous tissue, and detected in adults and also called as benign mesenchymomas [3]. Fibrolipomas may develop in virtually any region of the body that contains fat, but in general, they tend to appear on the trunk, neck and upper extremities [4]. Pubic area is one of the rare reported regions for fibrolipoma in the literature. A few cases of pubic fibrolipoma were reported in the literature and all the cases were among HIV $(+)$ patients with lipodystrophia, but none of them exceeded $10 \mathrm{~cm}$ in diameter [5]. The fibrolipoma is considered "giant" when reaches a diameter over $10 \mathrm{~cm}$ or weight over 1,000 gr $[6,7]$. Mesenteric, para-pharyngeal, esophageal and intraoral regions were reported as fibrolipoma localizations in the literature [6-8]. A case of giant fibrolipoma that mimics abdominal lipodystrophia was also reported [9]. The treatment of fibrolipomas involves surgical excision and appropriate reconstruction. Recurrence of excised fibrolipomas has not been reported in the literature; however, there are reports of neglected cases, which eventually developed malignant transformation [4]. Our case is not only the first pubic giant fibrolipoma but also the first case in normal individual not HIV (+) or lipodistrophic patient.

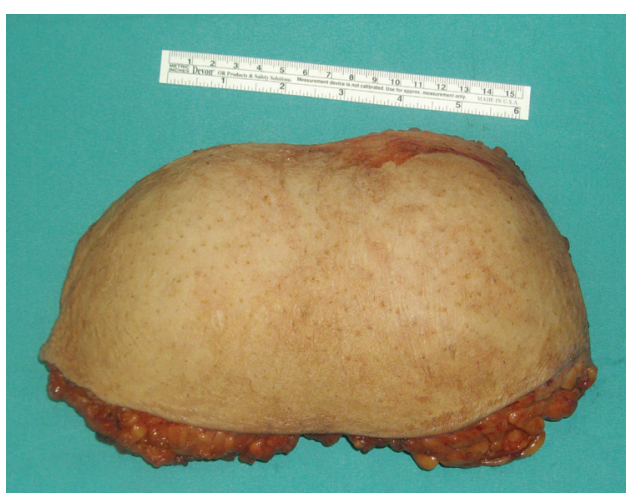

Figure 3. Excised neoplasm with overlaying skin.

\section{References}

1. Lucas GL. Benign soft tissue tumors. In Russell RC, ed. Plastic Surgery Indications, Operations and Outcomes, St Louis: Mosby; 2000:2277-2286.

2. Kohler S. Muscle, adipose and cartilage neoplasms. In Bolognia Jl, Jorizzo Jl, Rapini RP, eds. Dermatology, Edinburgh: Mosby; 2003:1883-1898.

3. Kransdorf MJ, Moser RP, Jr., Meis JM, Meyer CA. Fatcontaining soft-tissue masses of the extremities. Radiographics 1991;11(1):81-106.

4. Simsek T, Sonmez A, Aydogdu IO, Eroglu L, Karagoz F. Giant fibrolipoma with osseous metaplasia on the thigh. J Plast Reconstr Aesthet Surg 2011.

5. Guaraldi G, Orlando G, Squillace N, Roverato A, De Fazio D, Vandelli M, Nardini G, et al. Prevalence of and risk factors for pubic lipoma development in HIV-infected persons. J Acquir Immune Defic Syndr 2007;45(1):72-76.

6. Oliveros-Chaparro C, Bogarin-Rodriguez J, SanchezMendez M. [Giant fibrolipoma of the floor of the mouth. Presentation of a clinical case]. Invest Clin 2001;42(2):147-152.

7. Perez B, Campos ME, Rivero J, Lopez-Aguado D. Giant esophageal fibrolipoma. Otolaryngol Head Neck Surg 1999;120(3):445-446.

8. Janas A, Grzesiak-Janas G. [The rare occurence of fibrolipomas]. Otolaryngol Pol 2005;59(6):895-898.

9. Coban YK, Coskun A. Giant fibrolipoma mimicking abdominal lipodystrophy. Indian J Plast Surg 2008;41(1):97-98. 